\title{
Reliability and validity of the Mexican teachers' physical activity questionnaire (MTPAQ) in a subsample of female Mexican teachers
}

\author{
C. Medina' ${ }^{1}$ A. Monge ${ }^{2}$, M. Romero ${ }^{3}$, R. López-Ridaura ${ }^{4}$, S. Barquera ${ }^{1}$, I. Romieu ${ }^{5}$, E. Denova-Gutiérrez ${ }^{1 *}$ and \\ M. Lajous $^{2}$
}

\begin{abstract}
Background: Reliable and valid instruments are needed to estimate physical activity levels. The purposes of this study were to estimate the reliability and validity of the Physical Activity Questionnaire (MTPAQ) in a subsample of the Mexican Teachers Cohort study.

Methods: We completed telephone interviews and clinical examinations of 82 teachers. Two MTPAQ, five International Physical Activity Questionnaire (IPAQ)-long form, and two accelerometer (AC) measures were used to determine physical activity levels throughout 24 months. Moderate and walking physical activity (MWPA min/week), vigorous physical activity (VPA min/week), and moderate-to-vigorous physical activity minutes per week (MVPA min/week) were estimated for each instrument. Pearson, Intra-class correlations and deattenuated adjustments were used to determine the reliability and validity of MTPAQ.

Results: MWPA and MVPA min/week of MTPAQs were moderately correlated ( $r \geq 0.54)$ to min/week of IPAQ-long form. MWPA and MVPA min/week average MTPAQ and MTPAQ1 and average AC, AC1 and AC2 were fairly correlated $(r \geq 0.20)$. A higher correlation was observed when correlation coefficients were attenuated $(r \geq 0.32)$.
\end{abstract}

Conclusions: MTPAQ1 is a reliable and valid tool to measure physical activity levels.

Keywords: Reproducibility, Validity, Teachers, Mexico, Questionnaires

\section{Background}

Engaging in physical activity is a well-known health behavior that is recommended to prevent and manage certain chronic diseases [1]. In addition, physical activity is a necessary parameter that needs to be estimated in most health studies. The Mexican Teachers Cohort (MTC) is a prospective study of 115,345 female teachers

\footnotetext{
*Correspondence: edgar.denova@insp.m

${ }^{1}$ Center for Nutrition and Health Research, Mexican National Institute of Public Health (INSP), Avenida Universidad 655, Santa María Ahuacatitlán, 62100 Cuernavaca, Morelos, Mexico

Full list of author information is available at the end of the article
}

established in 2006-2008 that evaluates lifestyle, including physical activity and environmental risk factors mainly focused on cancer and cardiovascular diseases [2].

Several questionnaires have been developed to estimates physical activity levels [3]. These questionnaires are different with respect to activity domains (leisure, work-related, transportation, household), intensities, energy measure (kcal, METs), time frame (weekend, last week, last month, last year), and style (questionnaire, index, record).[3] However, selection of a questionnaire not only depends on these characteristics but also on the purpose of the study [3]. 


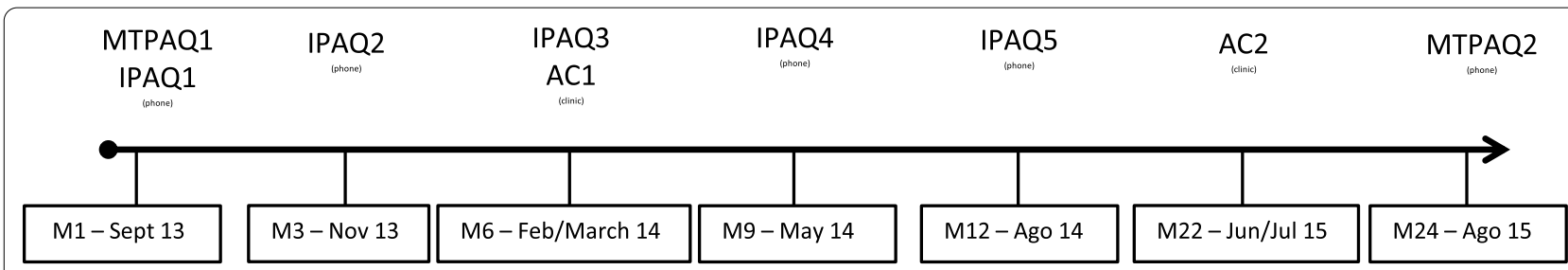

M - Month

IPAQ - International Physical Activity Questionnaire - long form

AC-Accelerometer

MTPAQ - Mexican Teacher's Physical Activity Questionnaire

Fig. 1 Subjective and objective physical activity assessment through 24 months. M month, IPAQ International Physical Activity Questionnairelong form, AC Accelerometer

As part of the MTC, a literature review of instruments that measures physical activity levels was performed. However, none of the available questionnaires were validated in Mexican women nor in teachers, neither had the characteristics and dimension to be used in a cohort study. Thus, the MTC adapted the Stanford Physical Activity Questionnaire [4] to create the Mexican Teachers' Physical Activity Questionnaire (MTPAQ) [5]. This tool measures the average hours per week spent walking and doing moderate and vigorous (working and leisure time) physical activity in the last 12 months.

Based on previous studies, the mean test-retest reliability for physical activity questionnaires is 0.80 [6]. In addition, a correlation value of 0.30 has been observed between questionnaires and accelerometers [6]. However, this result could be higher if an attenuation adjustment was applied [7]. Until know, there is a lack of information related to psychometric tests of the MTPAQ. The purposes of this study were to determine the reliability and validity of the MTPAQ used in the MTC.

\section{Materials and methods}

\section{Participants}

A random sample of 161 MTC participants aged 35 and older living in Mexico City were invited to participate in the current validation study in 2013. Ninety-nine teachers agreed to participate, signed the consent letter, answered a physical activity, and underwent a clinical evaluation in Mexico City. Written informed consent was obtained from all participants. There were no statistically significant differences in mean BMI, weight, height and waist circumferences, except for age (48 vs. 49 years, $p<0.05$, respectively) between those that participated and did not in the telephone interviews and clinical examinations.

\section{Sample size}

Based on previous studies, we estimated that at least 30 participants were enough to assess the correlation between IPAQ-long form versus MTPAQ and accelerometer versus MTPAQ $[3,8]$.

\section{Procedure}

We conducted telephone interviews and clinical examinations of 82 teachers during 24 months. Teachers responded to the Mexican Teacher's Physical Activity Questionnaire (henceforth: MTPAQ) by phone at month 1 (MTPAQ1) and 24th (MTPAQ2). In the first month, the International Physical Activity Questionnaire (IPAQ)long form (IPAQ1) was answered by phone and teachers underwent anthropometric tests. A second IPAQ-long form was responded by phone at month 3 (IPAQ2). In the sixth month, teachers received an Actical accelerometer (Mini Mitter Company, Bend, OR, USA). They were asked to wear this device during 9 consecutive days at all the times except when in water activities (ex.: bath, swim). Additionally, a pamphlet that contained instruction on wearing and removing an accelerometer, FAQ, and support contacts were given. Nine days later, accelerometers were removed and another IPAQ-long form was answered (IPAQ3). At months 9 and 12 teachers responded others IPAQ-long form (IPAQ4 and IPAQ5, respectively). Finally, a subsample of 69 teachers used an Actical accelerometer (AC2) for 9 consecutive days during month 22. (Fig. 1). The National Institute of Public Health Ethic Review Board of Mexico approved this study (number 1130).

\section{Mexican Teachers Physical Activity Questionnaire (MTPAQ)}

This is a 5-item questionnaire, and asks for the average number of hours per week spent walking, and doing moderate and vigorous physical activities during work and leisure time over the past 12 months (Fig. 2). The Spanish version is included as a Additional file 1. 


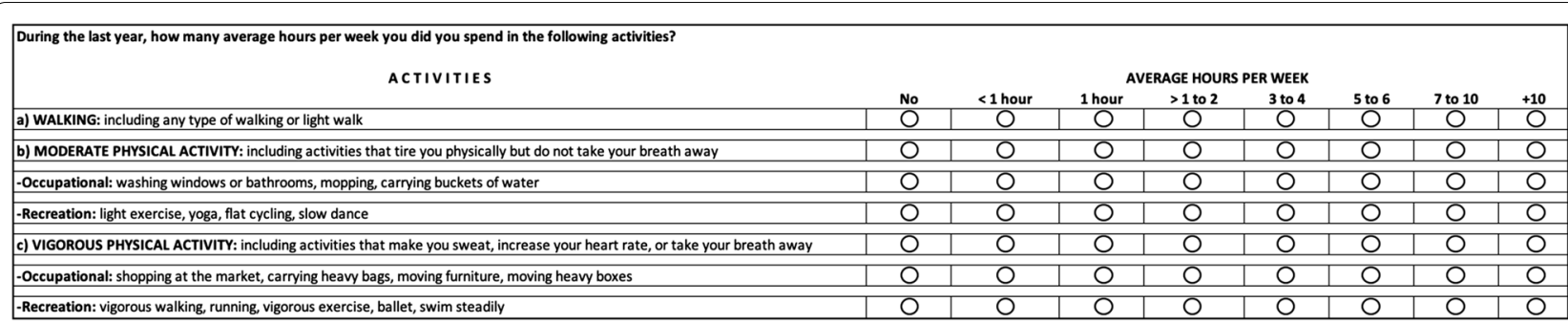

Fig. 2 Mexican Teachers Physical Activity Questionnaire (MTPAQ). English version

Criteria for MTPAQ data cleaning were as follows: (1) data collected in hour per category were converted into minutes: not performing physical activity $(0 \mathrm{~min}),<1 \mathrm{~h}$ (30 min), 1:00 h (60 min), > 1:01 to $2: 59 \mathrm{~h}(120 \mathrm{~min}), 3: 00$ to $4: 59 \mathrm{~h}(210 \mathrm{~min}), 5: 00$ to $6: 59 \mathrm{~h}(330 \mathrm{~min}), 7: 00$ to 10:00 h (510 min), > 10:00 h (600 min); (2) "do not know", "refused" or "missing data" for duration or frequency were removed from the analysis. As used in the IPAQ, truncation was performed for all daily duration values exceeding $180 \mathrm{~min}$ for walking, moderate and vigorous physical activity.

Minutes per week of walking and moderate (MWPA) and vigorous physical activity (VPA) during work and leisure time were summed to create a measure of total moderate-to-vigorous physical activity (MVPA) minutes per week.

\section{IPAQ-long form}

The International Physical Activity Questionnaire is a 31-item questionnaire that could be self-administered, conducted face-to-face, or answered by telephone [8]. The questionnaire asks about physical activities achieved during leisure time, at home, at yard and at work. In addition, this questionnaire inquiries about active transportation, walking and sedentary activities performed for at least 10 continuous minutes in the previous 7 days [8].

The IPAQ protocol was used to clean up IPAQ values [9]. Information related to data cleaning procedure has been published elsewhere [9].

Minutes per week of moderate (MPA), walking (WPA) and vigorous physical activities (VPA) performed during the four domains (leisure time, home, work and transportation) were summed to generate a measure of MVPA minutes per week.

\section{Actical ${ }^{\circledR}$ accelerometer}

This is a waistband-mounted omnidirectional device. The Actical accelerometer has been used and validated in adults [10].

The Personal Activity and Location Measurement System (University of California, San Diego, California,
United States) and IBM SPSS software; version 24 (SPSS Inc., an IBM company Chicago Illinois, United States) were used to clean the dataset. Compliance criteria was defined based on previous studies [11]. Accelerometer data output is expressed in total counts (counts$\left.\min ^{-1}\right)$. These counts were stratified as sedentary $(\leq 1.5$ Mets, $<100$ accelerometer counts), light (1.5 to 2.9 Mets, 100 to $<1500$ accelerometer counts), moderate (3.0 to 5.9 Mets, 1500 to $<6500$ accelerometer counts), or vigorous ( $\geq 6$ Mets, $\geq 6500$ accelerometer counts) [10, 11]. Moderate-to-vigorous physical activities that occurred in $\geq 10$ consecutive counts (with allowance of 2 min per each 10 min below the 1530 epoch cut-point) in each valid day were summed to generate VPA, MPA and MVPA minutes per week [11].

\section{Physical activity prevalence}

This prevalence was estimated for MTPAQs, IPAQs-long form and ACs. WHO physical activity recommendations were used to classified individuals as inactive $(<150 \mathrm{~min} /$ week of MVPA) and active ( $\geq 150 \mathrm{~min} /$ week of MVPA) [12].

\section{Anthropometry}

Weight and height were measured to the nearest $0.1 \mathrm{~kg}$ and $0.1 \mathrm{~cm}$, and the Body Mass Index (BMI) was calculated as $\mathrm{kg} / \mathrm{m}^{2}$. BMI status was based on the WHO adult cut points as: underweight $\left(<18.5 \mathrm{~kg} / \mathrm{m}^{2}\right)$, normal weight $\left(18.5-24.9 \mathrm{~kg} / \mathrm{m}^{2}\right)$, overweight $\left(25.0-29.9 \mathrm{~kg} / \mathrm{m}^{2}\right)$, or obese $\left(\geq 30.0 \mathrm{~kg} / \mathrm{m}^{2}\right)$. The BMI variable was divided into two categories: normal weight $\left(<24.9 \mathrm{~kg} / \mathrm{m}^{2}\right)$ and overweight/obese $\left(\geq 25.0 \mathrm{~kg} / \mathrm{m}^{2}\right)$. [13]

\section{Statistical analysis}

Means, standard deviation, interquartile ranges and proportions were used to describe the sample. Physical activity variables were tested for normality using Kolmogorov-Smirnov test and those that did not meet normality criteria were logarithmically transformed. Mean minutes per week between MTPAQ1 and MTPAQ2 were 
compared using student t-test. Reliability and validity for the log-transformed MPA or MWPA, VPA and MVPA were assessed using Pearson and intra-class correlation coefficients (two-way mixed, average measurements and absolute agreement). Deattenuation adjustment was generated based on the Rosner and Willett recommendations [7]. The $95 \%$ CI were obtained by bootstrapping the distribution of means for all PA intensities.

The association between MTPAQ (1, 2, average) minutes per week of MVPA and AC $(1,2$, average) minutes per week of MVPA was assessed by a linear regression. The intercept and slopes of the regression line and their associated $95 \% \mathrm{CI}$ was estimated to observe if values were different from 0 and 1 , respectively. Level of significance was set at $p<0.05$.

Cohen's kappa coefficients were used to estimate the correlation of the prevalence of physical inactivity/ activity between MTPAQ versus IPAQ-long form and MTPAQ versus AC.

For the purpose of this study, coefficient values were classified as follows: $<0.21$ were poor, 0.21 to 0.40 were fair, 0.41 to 0.60 were moderate, 0.61 to 0.80 were strong and 0.80 to 1 were very strong [14].

\section{Results}

There were 82 women who answered the MTPAQs, while 86 did the IPAQs, and on average, 61 had two valid accelerometer values. From those that answered both MTPAQs, $42.7 \%$ were aged $<45$ years, $25.6 \%$ had obesity and $36.6 \%$ had waist circumference $\geq 90 \mathrm{~cm}$ (Table 1).

According to Table 2, significant differences were found in VPA minutes per week (164 vs. $101 \mathrm{~min}, p=0.001$ ). MTPAQ1 and MTPAQ2 minutes per week for all intensities were significantly correlated to each other $(p<0.02)$, ranging from $r: 0.26$ to $r: 0.56$.

Table 1 Characteristics of participants in a study on the reliability and validity of MTPAQ and IPAQ long-form $(n=82)$. Mexico, 2013-2015

\begin{tabular}{lll}
\hline Variables & $\mathbf{N}$ & \% $(\mathbf{9 5 \%} \mathrm{Cl})$ \\
\hline Age & 35 & \\
$<45$ years & 47 & $42.7(31.8,54.1)$ \\
$\geq 45$ years & & $57.3(45.9,68.2)$ \\
Body mass index & 19 & $23.2(14.6,33.8)$ \\
Normal weight & 42 & $51.2(39.9,62.4)$ \\
Overweight & 21 & $25.6(16.6,36.4)$ \\
Obese & & \\
Waist circumference & 52 & $63.4(52.0,73.8)$ \\
$<90 \mathrm{~cm}$ & 30 & $36.6(26.2,48.0)$ \\
$\geq 90 \mathrm{~cm}$ & &
\end{tabular}

95\% Cl Confidence interval, $N$ number
Table 2 Mean minutes per week and standard deviation for the month-specific levels and reliability coefficients for MTPAQ1 and MTPAQ2. Mexico 2013-2015

\begin{tabular}{lllll}
\hline Variables & $\mathbf{1}(\mathbf{n}=\mathbf{8 2})$ & $\mathbf{2}(\mathbf{n}=\mathbf{8 2})$ & Average $(\mathbf{n}=\mathbf{8 2})$ & $\begin{array}{l}\text { Log min/week) } \\
\text { Pearson } \mathbf{r} \\
\mathbf{( 9 5 \% ~ C l )}\end{array}$ \\
\hline MWPA & $376(300)$ & $332(268)$ & $354(237)$ & $0.56^{*}(0.45,0.88)$ \\
VPA & $164(185)^{*}$ & $101(144)$ & $132(144)$ & $0.26^{*}(0.04,0.42)$ \\
MVPA & $539(417)$ & $432(360)$ & $485(334)$ & $0.54^{*}(0.40,0.82)$ \\
\hline
\end{tabular}

Based on intra-class correlation coefficient (ICC) estimates, a statistically significant correlation was found between MTPAQ1, MTPAQ2 and average IPAQs longform (range: $r=0.45$ to $r=0.80$ ) for all PA intensities. (Table 3) Slightly higher correlations were observed for MWPA and MVPA between average MTPAQs and average IPAQs.

According to Table 3, the correlation between the minutes per week of average MTPAQ, MTPAQ1 and MTPAQ2 and minutes per week of average AC, AC1 and AC2 was statistically significant for MVPA (ranged from $r=0.20$ to 0.39 ) and MWPA (ranged from $r=0.22$ to 0.37 ), except for the correlation between minutes per week of MWPA MTPAQ1 versus AC1 and MTPAQ2 versus AC2. The associations between MVPA and MWPA $\mathrm{min} /$ week, in some cases, were higher in the deattenuated correlations.

As shown in Fig. 3, when MVPA minutes per week of average $\mathrm{AC}, \mathrm{AC} 1$ and $\mathrm{AC} 2$ was used to predict MVPA minutes per week of MTPAQ1, respectively, the intercepts were ranged from 1.41 to $1.62(p<0.01)$ and the slopes were ranged from 0.18 to $0.23(p<0.05)$. The interception between both lines indicates that teachers within the lowest levels of physical activity observed by average $\mathrm{AC}$ and $\mathrm{AC} 2$ overestimate self-reported MVPA minutes of MTPAQ1. This overestimation diminishes as accelerometer values increase (interception $692 \mathrm{~min}$ and $724 \mathrm{~min}$, respectively). No statistically significant slopes were observed for the MTPAQs versus AC1, MTPAQ1 versus $A C 1, M T P A Q 2$ versus $A C s$ and MTPAQ2 versus $\mathrm{AC} 2(p<0.06)$.

Cohen's Kappa coefficient values between ACs and MTPAQs ranged from -0.02 to $0.12, p>0.05$. However, significantly values were observed between MTPAQs and IPAQs-long form ranged from 0.28 to $0.61, p<0.005$, being higher the agreement between average IPAQs and average MTPAQs (data not shown).

\section{Discussion}

Our findings indicated that MWPA and MVPA minutes per week of the MTPAQs were moderately correlated $(r \geq 0.54)$. Moreover, higher correlations were observed in 
Table 3 Pearson, intra-class and deattenuated correlations between log-transformed average minutes per week of log-transformed minutes per week of MTPAQs, five IPAQ long-forms, and two accelerometers. Mexico 2013-2015

\begin{tabular}{|c|c|c|c|}
\hline & \multicolumn{3}{|c|}{ Variables $(\mathrm{r}(95 \% \mathrm{CI}))$} \\
\hline & Pearson & ICC & Deattenuated \\
\hline \multicolumn{4}{|c|}{ MTPAQ1 versus Average IPAQ $(n=86)$} \\
\hline MWPA & $\begin{array}{l}0.58 \\
(0.52,0.99)\end{array}$ & $\begin{array}{l}0.72 \\
(0.57,0.82)\end{array}$ & $\begin{array}{l}0.92 \\
(0.67,0.99)\end{array}$ \\
\hline VPA & $\begin{array}{l}0.44 \\
(0.24,0.63)\end{array}$ & $\begin{array}{l}0.45 \\
(-0.09,0.70)\end{array}$ & $\begin{array}{l}0.99 \\
(0.89,0.99)\end{array}$ \\
\hline MVPA & $\begin{array}{l}0.61 \\
(0.58,1.04)\end{array}$ & $\begin{array}{l}0.72 \\
(0.56,0.82)\end{array}$ & $\begin{array}{l}0.95 \\
(0.74,0.99)\end{array}$ \\
\hline \multicolumn{4}{|c|}{ MTPAQ2 versus Average IPAQ $(n=75)$} \\
\hline MWPA & $\begin{array}{l}0.61 \\
(0.43,0.79)\end{array}$ & $\begin{array}{l}0.75 \\
(0.61,0.84)\end{array}$ & $\begin{array}{l}0.99 \\
(0.92,0.99)\end{array}$ \\
\hline VPA & $\begin{array}{l}0.42 \\
(0.21,0.63)\end{array}$ & $\begin{array}{l}0.54 \\
(0.25,0.72)\end{array}$ & $\begin{array}{l}0.85 \\
(0.43,0.99)\end{array}$ \\
\hline MVPA & $\begin{array}{l}0.64 \\
(0.45,0.81)\end{array}$ & $\begin{array}{l}0.77 \\
(0.64,0.86)\end{array}$ & $\begin{array}{l}0.99 \\
(0.92,0.99)\end{array}$ \\
\hline \multicolumn{4}{|c|}{ Average MTPAQ versus Average IPAQ $(n=75)$} \\
\hline MWPA & $\begin{array}{l}0.64 \\
(0.51,0.91)\end{array}$ & $\begin{array}{l}0.78 \\
(0.65,0.86)\end{array}$ & $\begin{array}{l}0.99 \\
(0.99,0.99)\end{array}$ \\
\hline VPA & $\begin{array}{l}0.54 \\
(0.27,0.57)\end{array}$ & $\begin{array}{l}0.47 \\
(-0.19,0.75)\end{array}$ & $\begin{array}{l}0.99 \\
(0.97,0.99)\end{array}$ \\
\hline MVPA & $\begin{array}{l}0.70 \\
(0.60,0.97)\end{array}$ & $\begin{array}{l}0.80 \\
(0.67,0.88)\end{array}$ & $\begin{array}{l}0.99 \\
(0.99,0.99)\end{array}$ \\
\hline \multicolumn{4}{|c|}{ MTPAQ1 versus Average $A C(n=61)$} \\
\hline MWPA & $\begin{array}{l}0.25 \\
(0.17,0.48)\end{array}$ & $\begin{array}{l}0.37 \\
(-0.44,0.62)\end{array}$ & $\begin{array}{l}0.31 \\
(0.03,0.57)\end{array}$ \\
\hline VPA & $\begin{array}{l}0.17 \\
(-0.07,0.37)\end{array}$ & $\begin{array}{l}0.29 \\
(-0.18,0.57)\end{array}$ & $\begin{array}{l}0.29 \\
(-0.09,0.65)\end{array}$ \\
\hline MVPA & $\begin{array}{l}0.26 \\
(0.01,0.36)\end{array}$ & $\begin{array}{l}0.39 \\
(-0.01,0.64)\end{array}$ & $\begin{array}{l}0.35 \\
(0.07,0.63)\end{array}$ \\
\hline \multicolumn{4}{|c|}{ MTPAQ2 versus Average $A C(n=59)$} \\
\hline MWPA & $\begin{array}{l}0.18 \\
(-0.08,0.44)\end{array}$ & $\begin{array}{l}0.20 \\
(-0.16,0.48)\end{array}$ & $\begin{array}{l}0.15 \\
(-0.17,0.48)\end{array}$ \\
\hline VPA & $\begin{array}{l}0.13 \\
(-0.14,0.39)\end{array}$ & $\begin{array}{l}0.15 \\
(-0.20,0.43)\end{array}$ & $\begin{array}{l}0.16 \\
(-0.24,0.53)\end{array}$ \\
\hline MVPA & $\begin{array}{l}0.21 \\
(-0.05,0.47)\end{array}$ & $\begin{array}{l}0.21 \\
(-0.16,0.49)\end{array}$ & $\begin{array}{l}0.32 \\
(-0.19,0.50)\end{array}$ \\
\hline \multicolumn{4}{|c|}{ Average MTPAQ versus Average $A C(n=59)$} \\
\hline MWPA & $\begin{array}{l}0.22 \\
(-0.04,0.48)\end{array}$ & $\begin{array}{l}0.22 \\
(-0.16,0.50)\end{array}$ & $\begin{array}{l}0.28 \\
(-0.02,0.55)\end{array}$ \\
\hline VPA & $\begin{array}{l}0.22 \\
(-0.04,0.48)\end{array}$ & $\begin{array}{l}0.13 \\
(-0.14,0.39)\end{array}$ & $\begin{array}{l}0.25 \\
(-0.21,0.66)\end{array}$ \\
\hline MVPA & $\begin{array}{l}0.25 \\
(-0.01,0.50)\end{array}$ & $\begin{array}{l}0.20 \\
(-0.16,0.49)\end{array}$ & $\begin{array}{l}0.32 \\
(0.03,0.59)\end{array}$ \\
\hline \multicolumn{4}{|c|}{ MTPAQ1 versus $A C 1(n=87)$} \\
\hline MWPA & $\begin{array}{l}0.16 \\
(-0.06,0.37)\end{array}$ & $\begin{array}{l}0.19 \\
(-0.13,0.43)\end{array}$ & $\begin{array}{l}0.22 \\
(-0.08,0.53)\end{array}$ \\
\hline VPA & $\begin{array}{l}0.22 \\
(-0.01,0.43)\end{array}$ & $\begin{array}{l}0.16 \\
(-0.14,0.42)\end{array}$ & $\begin{array}{l}0.39 \\
(0.02,0.70)\end{array}$ \\
\hline MVPA & $\begin{array}{l}0.20 \\
(0.01,0.41)\end{array}$ & $\begin{array}{l}0.20 \\
(-0.13,0.45)\end{array}$ & $\begin{array}{l}0.30 \\
(-0.01,0.56)\end{array}$ \\
\hline \multicolumn{4}{|c|}{ MTPAQ1 versus $A C 2(n=65)$} \\
\hline MWPA & $\begin{array}{l}0.33 \\
(0.09,0.57)\end{array}$ & $\begin{array}{l}0.33 \\
(-0.13,0.61)\end{array}$ & $\begin{array}{l}0.49 \\
(0.09,0.86)\end{array}$ \\
\hline
\end{tabular}


Table 3 (continued)

\begin{tabular}{|c|c|c|c|}
\hline & \multicolumn{3}{|c|}{ Variables $(\mathrm{r}(95 \% \mathrm{Cl}))$} \\
\hline & Pearson & ICC & Deattenuated \\
\hline VPA & $\begin{array}{l}0.12 \\
(-0.13,0.37)\end{array}$ & $\begin{array}{l}0.09 \\
(-0.14,0.33)\end{array}$ & $\begin{array}{l}0.19 \\
(-0.28,0.62)\end{array}$ \\
\hline MVPA & $\begin{array}{l}0.30 \\
(0.05,0.53)\end{array}$ & $\begin{array}{l}0.26 \\
(-0.16,0.54)\end{array}$ & $\begin{array}{l}0.46 \\
(0.07,0.83)\end{array}$ \\
\hline \multicolumn{4}{|c|}{ MTPAQ2 versus $A C 2(n=63)$} \\
\hline MWPA & $\begin{array}{l}0.14 \\
(-0.12,0.39)\end{array}$ & $\begin{array}{l}0.15 \\
(-0.17,0.42)\end{array}$ & $\begin{array}{l}0.19 \\
(-0.25,0.55)\end{array}$ \\
\hline VPA & $\begin{array}{l}0.07 \\
(-0.19,0.33)\end{array}$ & $\begin{array}{l}0.08 \\
(-0.24,0.35)\end{array}$ & $\begin{array}{l}0.12 \\
(-0.39,0.55)\end{array}$ \\
\hline MVPA & $\begin{array}{l}0.15 \\
(-0.11,0.40)\end{array}$ & $\begin{array}{l}0.15 \\
(-0.16,0.41)\end{array}$ & $\begin{array}{l}0.21 \\
(-0.27,0.58)\end{array}$ \\
\hline
\end{tabular}

ICC intraclass correlation, MTPAQ Mexican Teachers Physical Activity Questionnaire, IPAQ International Physical Activity Questionnaire-long form, AC accelerometer , MWPA moderate and walking activities, VPA vigorous physical activity, MVPA moderate-to-vigorous physical activity, Bold type statistically significant correlations
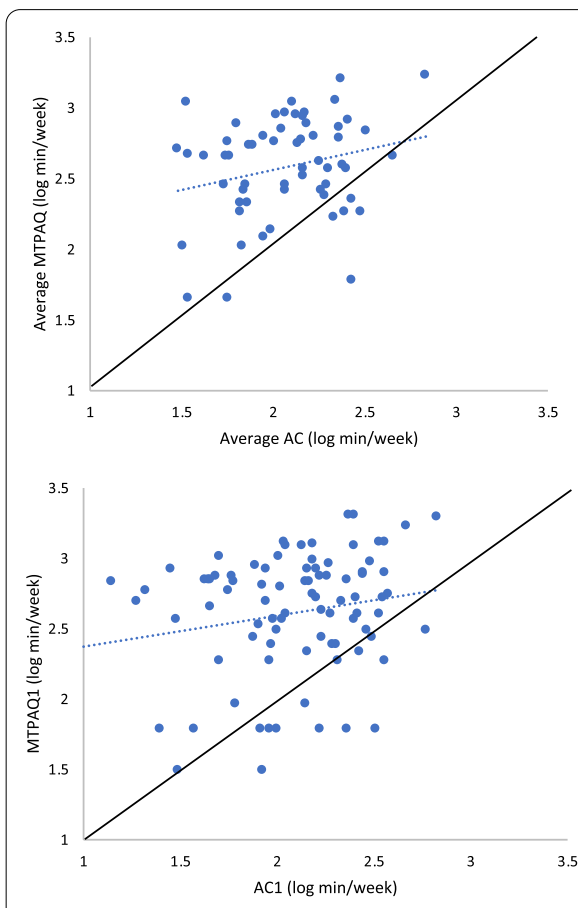

- Line of identity

--- Pearson correlation

Fig. 3 Log transformed minutes per week of MVPA between accelerometers and MTPAQs. Mexico, 2015
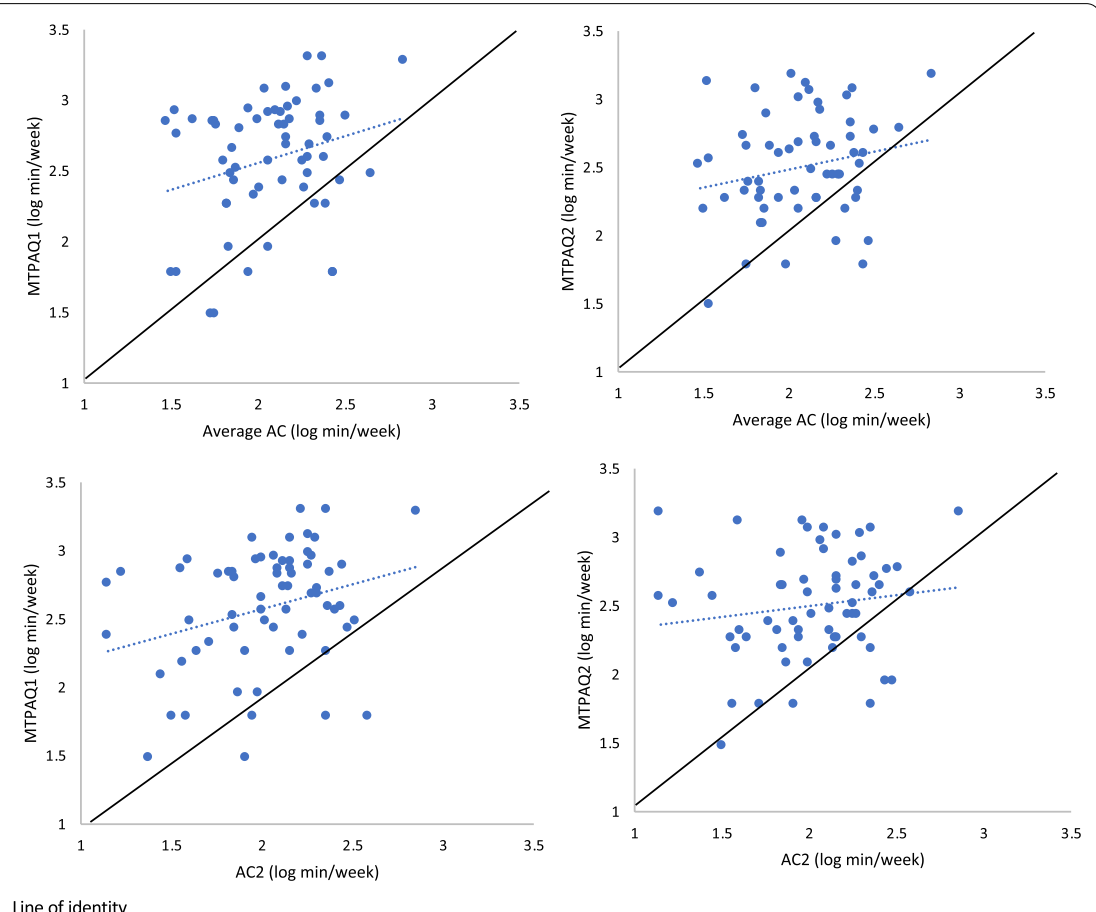

MWPA and MVPA minutes per week between MTPAQ and IPAQ ( $r \geq 0.72$ ). Finally, MWPA and MVPA min/ week average MTPAQ and MTPAQ1 versus average AC, $\mathrm{AC} 1$ and $\mathrm{AC} 2$ were fairly correlated $(\mathrm{r} \geq 0.20)$. In some cases, the correlations were higher when the deattenuation adjustment was applied.

Based on previous studies, the reliability for MVPA was lower in our study [15]. Some explanations of this result could be related to the fact that most of the previous studies that reported higher correlation values had a shorter time period between surveys $[6,15]$. In addition, a lower correlation was found for VPA compared to other intensities. This contradicts other studies that reported that MWPA showed the lowest reliability estimates [16]. This result could be related to the fact that teachers reported a lower number of minutes of VPA 
compared to MWPA, and the difficulty in differentiating between intensities.

MVPA and MWPA estimates from the MTPAQ1 and MTPAQ2 were strongly correlated with those reported by the average IPAQ long-form $(r=0.72,0.77$ and $r=0.72,0.75$, respectively). Similar results have been found in a study that measured the correlation between IPAQ long-form and IPAQ short-form in a study of 20 countries $(r=0.67)$ [8]; a higher correlation was found $(r=0.79)$ for total physical activity between IPAQ longform and New Zealand Physical Activity Questionnaire [17]. Some of the explanations of these differences could be the time frame of the recall [18], and the differences in domains between questionnaires [18].

The correlation of the MVPA min/week between the average MTPAQ, MTPAQ1 and average AC, AC1 and $\mathrm{AC} 2$ was fair (ranged from 0.20 to 0.39 ). However, there was no significant correlation of MVPA min/ween between MTPAQ2 and average AC, AC2. Compared to other self-report instruments, diverse correlation values have been observed in different settings and countries for other self-reported physical activity questionnaires $(r=0.14-0.53)$ [15]. One possibility for the differences in the correlation could be due to the fact that only 2 different weeks may not represent the physical activity levels over 24 months. Other reasons could be participants' difficulty in estimating their physical activity intensity [19], and social desirability bias, producing an overestimation of physical activity levels [19]. A reason for the non-correlation between MTPAQ2 and average AC, AC2 may be because the MTPAQ2 was answered 1 year and 6 months (AC1) and 1-2 months (AC2) after of the accelerometer measurement. This may not represent physical activity reported by the MTPAQ2.

Some studies have applied an attenuation adjustment to reduce the random error between repeated measurements. These adjustments have been mostly applied to nutrition measurements [7], however, few studies have been published in the physical activity area [20-22]. As shown in this study, other studies that calculated deattenuated correlations in physical activity instruments found that $r$ values seem to be higher compared to correlations that are not deattenuated [23].

\section{Strengths and limitations}

Neither the MTPAQ nor the IPAQ long-form are "gold standard" measures of physical activity, however, the IPAQ long-form could be used to estimate concurrent validity. Based on previous studies, similar estimates have been observed when comparing questionnaires. This is one of the few studies that validated the MTPAQ in a Mexican sample. Although participants used the Actical accelerometer day and night during 7 days, we asked them to remove their device every time they had contact with water. This could result in underestimation of the physical activity. Another limitation of the study includes the long period of time that elapsed between the first and the second MTPAQ and AC measurement. Although we missed physical activity levels measured with the MTPAQ at month 12th, we estimated the correlation between average IPAQ-long form versus MTPAQ1 and MTPAQ2. Finally, this study was limited to Mexican teachers who may not represent all women and teachers from Mexico.

\section{Conclusion}

The MTPAQ had a strong reliability for MWPA and MVPA. High correlation values were observed between MTPAQ and IPAQ-long forms for MWPA and MVPA $(r>60)$. Minutes per week of MVPA for MTPAQ1 had fair validity values when compared to accelerometer estimates (average, AC1 and AC2). MTC is one of the few women cohort studies in Mexico, this information will serve to estimate and/or correct physical activity levels within the study.

\section{Abbreviations}

AC: Accelerometer; BMI: Body mass index; Cl: Confidence interval; FAQ: Frequently asked questions; IPAQ: International Physical Activity Questionnaire; Min/week: Minutes per week; MPA: Moderate physical activity; MTC: Mexican Teachers Cohort; MTPAQ: Physical Activity Questionnaire used in the Mexican Teachers Cohort; MVPA: Moderate-to-vigorous physical activity; MWPA: Moderate and walking physical activity; VPA: Vigorous physical activity.

\section{Supplementary Information}

The online version contains supplementary material available at https://doi. org/10.1186/s13102-021-00371-4.

Additional file 1. Mexican Teachers Physical Activity Questionnaire (MTPAQ). Spanish version.

\section{Acknowledgements}

This work was supported by the American Institute of Cancer Research. The authors want to thank Dr. Martin Lajous, the EsMaestras women for their participation in the study, and the field workers: Elsa Yunes-Díaz, Erin Comerford, Jaime Jaquez, Jose Isaias Rangel Rosas, Maricruz Morales, Martha Tamez, Nataly Mercado, and Rocío Santoyo Vistrain.

\section{Authors' contributions}

Conception and design: CM, AM, ML, SB, IR. Development of methodology: CM, AM, ML, RL. Acquisition of data: AM. Analysis and interpretation of data: $C M, A M, E D, M R$. Writing, review and revision of manuscript: $C M, A M, M L$, $R L, E D, S B, I R, M R$. Administrative, technical and material support: AM. Study supervision: ML, SB, IR. All authors read and approved the final manuscript.

\section{Funding}

This work was supported by the American Institute for Cancer Research grant number 10A035. CM received support from the CONACYT scholarship (CVU 359065). 


\section{Availability of data and materials}

The datasets used generated and analyzed during the current study are not publicly available in any public link but are available from the corresponding author on reasonable request.

\section{Declarations}

\section{Ethics approval and consent to participate}

The study was reviewed and approved by the Instituto Nacional de Salud Publica's institutional review board (No. 1130). Methods were carried out in accordance with relevant guidelines and regulations. Written informed consent was obtained from all participants.

\section{Consent for publication}

Not applicable.

\section{Competing interests}

The authors declare no conflict of interest.

\section{Author details}

${ }^{1}$ Center for Nutrition and Health Research, Mexican National Institute of Public Health (INSP), Avenida Universidad 655, Santa María Ahuacatitlán, 62100 Cuernavaca, Morelos, Mexico. ${ }^{2}$ Center for Research on Population Health, National Institute of Public Health, Mexico City, Mexico. ${ }^{3}$ Center for Research in Evaluation and Surveys, National Institute of Public Health, Mexico City, Mexico. ${ }^{4}$ National Center for Preventive Programs and Disease Control. Ministry of Health, Mexico City, Mexico. ${ }^{5}$ Section of Nutrition and Metabolism. International Agency for Research on Cancer, Lyon, France.

Received: 5 April 2021 Accepted: 1 November 2021

Published online: 10 November 2021

\section{References}

1. Lee IM, Shiroma EJ, Lobelo F, Puska P, Blair SN, Katzmarzyk PT, Lancet Physical Activity Series Working Group. Effect of physical inactivity on major non-communicable diseases worldwide: an analysis of burden of disease and life expectancy. Lancet. 2012;380(9838):219-29.

2. Romieu I. The Esmaestras study: a large cohort study among mexican teachers. J Epidemiol Community Health. 2011;65(1):A17-8.

3. Pereira MA, FitzerGerald SJ, Gregg EW, Joswiak ML, Ryan WJ, Suminski RR, Utter AC, Zmuda JM. A collection of Physical Activity Questionnaires for health-related research. Med Sci Sports Exerc. 1997;29(6 Suppl):S1-205.

4. Sallis JF, Haskell WL, Wood PD, Fortmann SP, Rogers T, Blair SN, Paffenbarger RS Jr. Physical activity assessment methodology in the Five-City Project. Am J Epidemiol. 1985;121(1):91-106.

5. Angeles-Llerenas A, Ortega-Olvera C, Perez-Rodriguez E, Esparza-Cano JP, Lazcano-Ponce E, Romieu I, Torres-Mejia G. Moderate physical activity and breast cancer risk: the effect of menopausal status. Cancer Causes Control. 2010;21(4):577-86.

6. Sallis JF, Saelens BE. Assessment of physical activity by self-report: status, limitations, and future directions. Res Q Exerc Sport. 2000;71(Suppl 2):1-14.

7. Rosner B, Willett WC. Interval estimates for correlation coefficients corrected for within-person variation: implications for study design and hypothesis testing. Am J Epidemiol. 1988;127(2):377-86.
8. Craig CL, Marshall AL, Sjostrom M, Bauman AE, Booth ML, Ainsworth BE, Pratt M, Ekelund U, Yngve A, Sallis JF, et al. International physical activity questionnaire: 12-country reliability and validity. Med Sci Sports Exerc. 2003;35(8):1381-95.

9. IPAQ-group: guidelines for data processing and analysis of the International Physical Activity Questionnaire (IPAQ)-Short and Long Forms. IPAQ Web site. https://sites.google.com/site/theipaq/. 2005.

10. Wong SL, Colley R, Connor Gorber S, Tremblay M. Actical accelerometer sedentary activity thresholds for adults. J Phys Act Health. 2011;8(4):587-91.

11. Colley R, Connor Gorber S, Tremblay MS. Quality control and data reduction procedures for accelerometry-derived measures of physical activity. Health Rep. 2010;21(1):63-9.

12. WHO. Guidelines on physical activity and sedentary behaviour. Geneva: WHO; 2020.

13. WHO. Obesity: preventing and managing the global epidemic. WHO technical report series no. 894. In: Geneva; 2000.

14. Landis JR, Koch GG. The measurement of observer agreement for categorical data. Biometrics. 1977;33(1):159-74.

15. Sallis JF, Saelens BE. Assessment of physical activity by self-report: status, limitations, and future directions. Res Q Exerc Sport. 2000;71(2 Suppl):S1-14.

16. Brown WJ, Trost SG, Bauman A, Mummery K, Owen N. Test-retest reliability of four physical activity measures used in population surveys. J Sci Med Sport. 2004;7(2):205-15

17. Boon RM, Hamlin MJ, Steel GD, Ross JJ. Validation of the New Zealand Physical Activity Questionnaire (NZPAQ-LF) and the International Physical Activity Questionnaire (IPAQ-LF) with accelerometry. Br J Sports Med. 2010;44(10):741-6.

18. Tehard B, Saris WH, Astrup A, Martinez JA, Taylor MA, Barbe P, Richterova B, Guy-Grand B, Sorensen TI, Oppert JM. Comparison of two physical activity questionnaires in obese subjects: the NUGENOB study. Med Sci Sports Exerc. 2005;37(9):1535-41

19. Vandelanotte CBI, Philippaerts R, Sjöström M, Sallis J. Reliability and validity of a computerized and dutch version of the International Physical Activity Questionnaire (IPAQ). J Phys Act Health. 2005;2:63-75.

20. Chasan-Taber S, Rimm EB, Stampfer MJ, Spiegelman D, Colditz GA, Giovannucci E, Ascherio A, Willett WC. Reproducibility and validity of a self-administered physical activity questionnaire for male health professionals. Epidemiology. 1996;7(1):81-6.

21. Chasan-Taber L, Erickson JB, Nasca PC, Chasan-Taber S, Freedson PS. Validity and reproducibility of a physical activity questionnaire in women. Med Sci Sports Exerc. 2002;34(6):987-92.

22. Ferrari $P$, Friedenreich $C$, Matthews $C E$. The role of measurement error in estimating levels of physical activity. Am J Epidemiol. 2007;166(7):832-40.

23. Trinh OT, Nguyen DN, van der Ploeg HP, Dibley MJ, Bauman A. Test-retest repeatability and relative validity of the Global Physical Activity Questionnaire in a developing country contest. J Phys Act Health. 2009;6:S46-53.

\section{Publisher's Note}

Springer Nature remains neutral with regard to jurisdictional claims in published maps and institutional affiliations.

Ready to submit your research? Choose BMC and benefit from:

- fast, convenient online submission

- thorough peer review by experienced researchers in your field

- rapid publication on acceptance

- support for research data, including large and complex data types

- gold Open Access which fosters wider collaboration and increased citations

- maximum visibility for your research: over 100M website views per year

At BMC, research is always in progress.

Learn more biomedcentral.com/submissions 